\title{
A VILA BUARQUE TORNA-SE HIPSTER: CONCEITOS GLOBAIS, EFEITOS LOCAIS
}

\author{
Maurício Fernandes de Alcântara ${ }^{1}$
}

Um fenômeno que tem sido presenciado nas últimas décadas em diversas grandes metrópoles ao redor do mundo é quando alguns bairros centrais, repletos de atrativos culturais, características históricas ou de infraestrutura, aos poucos começam a despertar o interesse de um público mais jovem, predominantemente progressista, "moderno" em suas formas de se vestir e consumir, e de alta renda. A ambiência urbana oferecida por esses bairros, a oferta de serviços e o relativo baixo custo para se instalar faz com que não apenas haja um fluxo de novos moradores, mas também a inauguração de uma série de estabelecimentos comerciais voltados a este público. Aos poucos, a concentração desse público hipster ${ }^{2}$ e dos novos comércios a ele voltado passa a ser tão intensa que a imprensa, guias de viagem, moradores e frequentadores no geral começam a reconhecer (ou a questionar) esta como a "nova identidade" do bairro perante o seu entorno e a cidade como um todo. Diversos estudos etnográficos relatam processos comparáveis em cidades tão diversas como Amsterdam, Chicago, Nova York, São Francisco, Tóquio, Toronto e Xangai (Lloyd, 2010; Miskolci, 2016; Moretti, 2013; Ocejo, 2017; Zukin, 1989, 2011; Zukin, Kasinitz e Chen, 2015).

Neste artigo, apresento uma série de reflexões a partir de uma etnografia que realizei entre 2016 e 2019 na Vila Buarque, bairro da região central de São Paulo que, nos últimos anos, tem passando por esse processo. A pesquisa teve como ponto de partida os novos comércios altamente segmentados e sofisticados que começaram a surgir em grande quantidade na região desde meados dos anos 2010 - como novos

\footnotetext{
${ }^{1}$ Universidade de São Paulo, Brasil. Email: maucantara@gmail.com ORCID id: https://orcid.org/0000-0002-2709-3396

${ }^{2}$ Como argumento em Alcântara (2019), hipster é uma categoria heteronômica, raramente utilizada pelos sujeitos para se referirem a si próprios, muitas vezes é utilizado de forma jocosa. O uso corrente do termo remete à geração de jovens de camadas médias e altas nos Estados Unidos, geralmente nascida nos subúrbios e que, ao chegarem à vida adulta, optam por se instalarem nos centros das grandes cidades para usufruírem de toda a diversidade urbana e possibilidades de consumo e lazer que não poderiam ser encontradas nos subúrbios. Por não possuir um significado delimitado, fixo e consensual, é sempre mobilizado de forma situacional e subjetiva: uma pessoa pode ser classificada como hipster porque frequenta um estabelecimento hipster, porque se veste como um hipster, porque possui hábitos hipsters, porque possui uma atividade profissional hipster, porque mora em um bairro hipster ou em uma casa decorada conforme tendências hipsters.
} 
bares, cafés, restaurantes e lojas de design. Rapidamente tais estabelecimentos passaram a ser percebidos por moradores e frequentadores do bairro como indicadores de que o bairro está mudando, e são espaços promissores para a compreensão das relações entre os públicos que o frequentam e a cidade em um sentido mais amplo. Ao frequentá-los, investigar a história da região, o histórico de ocupação dos imóveis, conversar com proprietários, atendentes, clientes e vizinhos, pude perceber que cada endereço permite uma observação privilegiada da convergência entre os interesses, redes de relações, projetos de vida e expectativas com relação ao mundo do trabalho por parte dos proprietários, e os gostos, modos de consumo e preferências de sociabilidade de seus frequentadores.

Em diversas pesquisas que relatam a concentração de hipsters em bairros centrais de diferentes cidades no mundo, esse fenômeno é comumente associado à gentrification $^{3}$ : encarecimento dos custos de vida locais, substituição gradativa de uma população anterior por um número crescente de novos ocupantes com maior poder aquisitivo e, por fim, a total reconfiguração da composição socioeconômica da região. Em outras ocasiões (Alcântara, 2018a; b, 2019), argumentei que embora a presença de hipsters seja comumente percebida como sintoma de que o bairro esteja sofrendo gentrification, os dois processos não são sinônimos. É possível que existam processos de gentrification em curso sem a presença de hipsters - como demonstra a pesquisa de Darren Smith (2008) sobre o enobrecimento provocado pelo afluxo de estudantes universitários, a de Martin Phillips (1993) sobre gentrification em ambientes rurais, ou o trabalho de Loretta Lees (2016) sobre a super-gentrification provocada pelos superricos.

Da mesma forma, o caso paulistano observado em minha pesquisa revela que é possível que o processo de "hipsterização" ocorra em bairros que sempre foram ocupados pelas camadas superiores e médias-superiores da população. Isso sugere que as transformações percebidas na Vila Buarque sejam mais reflexo de uma renovação geracional de pessoas pertencentes às mesmas camadas sociais do que a substituição de um perfil socioeconômico por outro. Em outras palavras, o processo de "hipsterização" observado na Vila Buarque até o momento não deflagrou um diferencial de renda entre

\footnotetext{
${ }^{3}$ Para fins de desambiguação, utilizo gentrification, em inglês e em itálico, para referir-me às definições analíticas e conceituais disputadas ao longo da ampla bibliografia acerca do tema; e "gentrificação", na forma aportuguesada e entre aspas, para me referir à forma como o termo é mobilizado nas falas cotidianas de diversos interlocutores, como uma categoria da prática (Bourdieu, 1977) referente às percepções das pessoas quanto às mudanças ao seu redor.
} 
antigos e novos ocupantes - um dos pré-requisitos necessários para que que o diagnóstico analítico da gentrification se confirme (Davidson e Lees, 2005; Smith, 1979). Entretanto, as conversas de campo revelaram um aspecto importante para o andamento da pesquisa: muitos interlocutores utilizavam espontaneamente o termo "gentrificação", como categoria da prática, para se referir às mudanças que eram percebidas no bairro. Eles não apenas demonstravam familiaridade com o conceito analítico (que, por várias décadas, permaneceu restrito ao léxico de pesquisadores dos estudos urbanos), como também se reconheciam de alguma forma como potenciais vetores de "gentrificação" do bairro - afinal, era a eles que os novos comércios se dirigiam. Ainda que fosse possível perceber divergências significativas entre premissas teóricas para o diagnóstico analítico da gentrification e os sintomas denunciados por alguns interlocutores, a frequência com que a "gentrificação" surgia espontaneamente nas falas das pessoas permitiu interpretar a "hipsterização" como um fenômeno de trânsito, tradução e materialização no contexto local e no espaço físico da cidade uma série de ideias, imagens, referências, valores, palavras e significados que são de ordem global. Como demonstrarei adiante, não apenas o termo hipster é importado do contexto de grandes metrópoles no Norte global, como também o são uma série de preferências estéticas, modos de consumo e um grande conjunto de posicionamentos políticos e formas de estar na cidade que são associadas à categoria. A denúncia da "gentrificação" como efeito colateral é uma das ideias que "viajam" juntamente com o conjunto de signos globais que conformam o fenômeno da "hipsterização".

Este artigo tem como objetivo propor uma reflexão sobre uma série de conceitos, categorias, valores estéticos e posicionamentos políticos que circulam em escala global, e que podem ser observados em uma etnografia sobre a "hipsterização" de um bairro central de uma grande metrópole latino-americana. Como será demonstrado, trata-se de processos de mediações cosmopolitas (Velho, 2010) de referências globais, operacionalizadas por pessoas com alto capital cultural e alto poder de realização de seus projetos de vida, e que se territorializam no espaço urbano em uma escala e uma velocidade suficientes para despertar o sentimento de que "o bairro está mudando". Como será demonstrado, tais importações não revelam apenas modismos ou estrangeirismos passageiros: trata-se também de um processo de reivindicação e consolidação de novas formas de estar na cidade e de pensá-la politicamente. 


\section{Uma apresentação da Vila Buarque}

Vila Buarque é um bairro na região central da cidade de São Paulo, localizado entre a República (um dos distritos que formam o Centro Histórico da cidade, juntamente com a Sé), e o Higienópolis (o primeiro bairro da elite da cidade, urbanizado na virada dos séculos XIX e XX, e que até hoje é ocupado por moradores de alta renda). Por estar nessa localização intermediária, a Vila Buarque faz parte de uma zona de transição (Müller, 1958: 175) entre as múltiplas funções, o dinamismo e a heterogeneidade do Centro, e o caráter predominantemente residencial e de alto padrão do Higienópolis. Efetivamente, alguns interlocutores ao longo da pesquisa nem sequer reconheciam a região como sendo Vila Buarque: em algumas ocasiões, a parte do bairro mais contígua ao Higienópolis era compreendida como parte do Higienópolis, e a parte mais contígua à República era percebida como sendo República. Também não foram raros os casos em que o bairro era classificado como sendo parte da Santa Cecília bairro vizinho com muitas características comparáveis às da Vila Buarque, tanto em termos de infraestrutura e perfil de moradores, como também pelo fato de também estar vivenciando o mesmo processo de "hipsterização" da região ${ }^{4}$.

Ao longo de sua história, a Vila Buarque sempre concentrou uma série de universidades (como a Universidade Mackenzie, diversas instalações da Universidade de São Paulo, a Faculdade de Medicina da Santa Casa de Misericórdia de São Paulo e a Fundação Escola de Sociologia e Política de São Paulo), instituições culturais e educacionais (como a Aliança Francesa, o Sesc Consolação, o Senac Consolação e a Biblioteca Monteiro Lobato), e diversos escritórios de arquitetura e instituições referenciais para a profissão (como o Instituto dos Arquitetos do Brasil, a Escola da Cidade e o Sindicato dos Arquitetos no Estado de São Paulo). Antes da inauguração do campus da USP no bairro do Butantã nos anos 1970, na Zona Oeste, nos anos 1970, a Vila Buarque era considerada o principal bairro universitário da cidade, ganhando até

\footnotetext{
${ }^{4}$ Não existem perímetros ou limites oficiais para os bairros da cidade de São Paulo. A setorização administrativa utilizada atualmente pela Prefeitura é composta por um total de 96 distritos, que por sua vez estão distribuídos sob a jurisdição de 32 prefeituras regionais. Um distrito pode ser composto por diversos bairros, cujos limites são atribuídos de forma subjetiva e não-consensual pela população em função de seus diferentes usos. Para fins metodológicos, o perímetro que proponho para esta pesquisa consiste em uma coincidência aproximada entre as ruas mencionadas na bibliografia sobre a história da Vila Buarque, as definições mencionadas por interlocutores, e minhas próprias percepções de fronteiras invisíveis que delimitam contrastes entre a Vila Buarque e os bairros que a circundam - o que resulta em um total de 26 quadras pertencentes aos distritos da Consolação e República, ambas administradas pela prefeitura regional da Sé.
} 
mesmo a alcunha de Quartier Latin paulistano. Mesmo após a transferência das faculdades de Arquitetura e Urbanismo, de Filosofia, Ciências e Letras, e de Administração e Economia da USP da Vila Buarque para a Cidade Universitária, o bairro manteve suas características de bairro boêmio, concentrando um número cada vez maior de estudantes das universidades que permanecem na região até hoje.

Além da transferência das unidades da USP, no início dos anos 1970 o bairro também foi dividido ao meio pelo Minhocão, emblemática via elevada construída para conectar o Centro e a Zona Oeste da cidade, e que desde sua construção suscita debates sobre os efeitos negativos que provoca em seu entorno (em função da poluição e do barulho gerado pelos veículos, da redução da luminosidade e consequente aumento da insegurança nas vias subjacentes à construção, além do impacto negativo que a engenharia bruta da construção provoca na paisagem). Concomitantemente a estes acontecimentos, na segunda metade do século XX a cidade vivenciou um contínuo processo de migração de suas centralidades econômicas no sentido sudoeste, o que resultou na reconfiguração gradativa dos significados e funções dos bairros do Centro ao longo dos anos (Frúgoli Jr., 2000). Para uma grande parte das elites, a região central foi gradativamente sendo percebida como uma no-go area: caótica, perigosa, suja, decadente, inabitável, cuja serventia se resumiria ao deslocamento, a serviços inevitáveis, e aos usos quase que exclusivos das camadas mais pobres da população. Apesar dessas transformações das funções e do perfil dos usos e ocupantes da região central ao longo das últimas décadas, bairros como Higienópolis, Vila Buarque e Santa Cecília mantiveram um perfil de ocupação por camadas superiores da população - e nunca foram considerados bairros passíveis de intervenção pública pelos diversos projetos de requalificação da região central propostos por diferentes gestões municipais das últimas décadas.

Ao longo dos anos 2010, entretanto, uma série de acontecimentos fizeram com que a região voltasse a ganhar atenção da imprensa e, principalmente, de um segmento mais jovem e de alinhamento político mais progressista das camadas superiores da população paulistana. A recém-inaugurada Linha 4 - Amarela do Metrô reforçou a conexão entre a região central e o eixo sudoeste da cidade. Após 2 anos de reforma, a Praça Franklin Roosevelt, na República, foi reinaugurada em 2012 e rapidamente transformou-se em um importante espaço de sociabilidade jovem na região central, integrando-se com a grande mancha (Magnani, 2012) de lazer noturno que havia se 
consolidado na segunda metade dos anos 2000 na Rua Augusta (cujo trecho entre a Avenida Paulista e o Centro passou a ser conhecido como "Baixo Augusta"). No mesmo ano, aconteceu a primeira edição do Festival Baixo Centro, festival organizado de forma autônoma e colaborativa para ocupar espaços públicos e equipamentos culturais em todo o entorno do Minhocão com atividades culturais durante uma semana. Entre 2013 e 2016, sob a gestão do então prefeito Fernando Haddad, o carnaval de rua passou a ganhar novas dimensões na cidade, a implementação de uma grande rede cicloviária e de novos corredores de ônibus despertaram intensos debates sobre mobilidade urbana, e a aprovação do Plano Diretor Estratégico em 2014 determinou, entre outras medidas, um prazo para o planejamento e implementação de uma nova destinação ao Minhocão - que deverá ser gradativamente desativado para a circulação de veículos. Além disso, manifestações políticas pontuais, como o "Churrascão da Gente Diferenciada" de 2011 (contra declarações de moradores do Higienópolis que criticavam a construção de uma estação de metrô no bairro, pois isso popularizaria o acesso ao bairro nobre) ou abrangentes, como as Jornadas de Junho de 2013, ajudaram a aumentar a sensibilidade de parte da população quanto à importância de se estar nos espaços públicos urbanos e de reivindicá-los.

\section{A Vila Buarque vira hipster}

Por volta de 2014, o poder aquisitivo elevado dos moradores, a alta circulação de estudantes, pesquisadores, arquitetos e frequentadores em geral, a alta qualidade de infraestrutura da região e os baixos preços dos imóveis fizeram com que alguns novos estabelecimentos comerciais abrissem as portas na região - mais especificamente no entorno da rua Doutor Cesário Mota Jr., na Vila Buarque, e da rua Barão de Tatuí, na Santa Cecília. Alguns exemplos foram uma cafeteria especializada em grãos especiais e técnicas sofisticadas de preparo de café, um restaurante que também funciona como loja de discos de vinis, uma antiga banca de jornais reformada para vender publicações de editoras independentes e para abrigar eventos culturais; um sebo e loja de discos que também funciona como espaço para eventos culturais. Aos poucos, foram surgindo novas "atrações" na região: um misto de loja de plantas com cafeteria; duas lojas de alimentos orgânicos baseadas em modelos de comércio justo, com os preços de custo dos produtos transparentes aos clientes; uma loja de velas decorativas produzidas sem 
insumos de origem animal; um bar com coquetéis preparados à base de chai masala; algumas cervejarias especializadas em cervejas artesanais; um bar especializado em vinhos naturais e biodinâmicos.

Apesar da evidente heterogeneidade de atividades, produtos e serviços oferecidos por cada espaço, todos esses lugares apresentam muitas características em comum. A primeira delas é que a quase totalidade destes estabelecimentos não é parte de nenhuma rede de lojas ou negócios: em geral, são lojas independentes, resultado dos investimentos pessoais (tanto em termos financeiros como de projetos de vida) de seus proprietários. Estes são pessoas que, em determinado momento de suas vidas, optaram por fazer transições profisssionais - abrindo mão de carreiras em outras áreas profissionais para apostar em atividades novas, às quais nunca haviam se dedicado anteriormente, mas que representavam uma nova oportunidade tanto de geração de renda, como de dedicação a novos projetos (Velho, 1994). Além dos potenciais ganhos financeiros provenientes destes negócios, o investimento também acontece com vistas a um ganho de capital social: praticamente nenhum destes estabelecimentos é voltado a um público amplo e heterogêneo, e em quase todos os casos, tanto o público a quem os locais se destinam quanto os proprietários e os profissionais que neles trabalham compartilham de repertórios de gostos, interesses, estilos de vida e padrão social, econômico e cultural comparáveis.

Outra característica comum a todos esses novos negócios é o alto nível de especialização de tudo o que é oferecido, sempre acompanhado de adjetivos que asseguram que o que está sendo consumido rejeita qualquer traço de banalidade ou comoditização. Não são quaisquer itens que podem ser encontrados em quaisquer outros lugares pela cidade - são artesanais, orgânicos, veganos, autorais, releituras, de produção independente. Mais do que mera estratégia de marketing para vender produtos por um maior preço e maior margem de lucro a consumidores de maior poder aquisitivo, essas características operam uma distinção que requer um repertório de gostos e referências estéticas que são compartilhados entre proprietários e frequentadores destes lugares:

a principal intenção não é distinguir-se das camadas mais baixas, tampouco provar para seus pares que estão em pé de igualdade ou de superioridade em termos econômicos: trata-se, antes disso, de ressaltar que estes são diferentes dentro de seus próprios contextos de sociabilidade, evidenciando que são mais modernos, "descolados", criativos, originais e cosmopolitas do que, por exemplo, seus familiares, colegas de trabalho ou antigos colegas de escola 
(que, mesmo sob o mesmo background sociocultural e econômico, não compartilham das mesmas preferências estéticas e de consumo). Estes procedimentos de diferenciação envolvem, por exemplo, a escolha de marcas que não necessariamente sejam mais caras, mais conhecidas ou mais exclusivas - mas sim daquelas cujo consumo requer um conjunto de conhecimentos e habilidades que não podem ser apreendidos apenas em função do poder econômico, e sim por uma maior sensibilidade ou conhecimento sobre a origem de tais produtos, a forma como são produzidos e comercializados e, sobretudo, as razões pelas quais são diferentes daqueles consumidos por seus pares 'não-hipsters' (Alcântara, 2019: 111-112).

Em diálogo com Pierre Bourdieu, essa recusa deliberada ao convencional ou ao mainstream assemelhar-se-ia aos processos de distinção adotados pelo esteta, que:

em conformidade com o que se vê em todos os casos em que ele se apropria de um dos objetos do gosto popular, western ou histórias em quadrinhos, introduz um distanciamento, uma diferença - dimensão de sua distinção distante - em relação à percepção de 'primeiro grau', deslocando o interesse do 'conteúdo', personagens, peripécias etc., em direção à forma, aos efeitos propriamente artísticos que se apreciam apenas relacionalmente pela comparação com outras obras, completamente exclusiva da imersão na singularidade da obra imediatamente dada (Bourdieu, 2011: 37).

Por fim, um terceiro aspecto em comum entre todos esses estabelecimentos são traços da decoração dos espaços. Praticamente todos têm fachadas discretas (quando não compostas apenas por uma pequena porta que dá acesso ao estabelecimento no piso superior); os ambientes muitas vezes são minimalistas, onde predominam cores neutras como o branco e o cinza; há o uso explícito de materiais baratos na composição do mobiliário, onde prevalecem madeiras que evidenciam suas cores e texturas naturais; plantas com grandes folhagens (como samambaias e costelas-de-adão) não são raras; na decoração, mesclam-se elementos vintage com design contemporâneo, e em vários casos são incorporadas para dentro do ambiente manifestações de arte de rua (como grafitti e lambe-lambes). Em todos os casos, nota-se uma espécie de improviso calculado, uma escolha deliberada por um acabamento inacabado que, ao mesmo tempo em que confere um ar de espontaneidade e criatividade ao ambiente, também reduz os custos para abertura destes pequenos negócios.

Se estes estabelecimentos fossem direcionados a um público amplo, possivelmente muitas dessas características poderiam ser interpretadas como desleixo ou como marcadores de lugares baratos, onde os preços praticados não se justificariam. No entanto, assim como ocorre com os produtos oferecidos, há uma conexão entre proprietários e clientes baseada na partilha de gostos e referenciais estéticos que 
validam essas características como legítimas, autênticas. Além disso, uma parte considerável dos proprietários destes estabelecimentos oriundos de profissões tidas como criativas, como arquitetura, design, publicidade, jornalismo, artes e humanidades em geral. Isso significa que, ao conceberem os espaços, investiram não apenas dinheiro e tempo, mas também seus próprios capitais culturais e sociais, seus próprios repertórios estéticos e suas competências profissionais para garantir que seus novos negócios teriam aderência junto a um público que pertence aos mesmos círculos sociais dos quais eles também fazem parte. Da mesma forma, empenham cotidianamente suas habilidades de comunicação para divulgar seus cenários e produtos nas redes sociais - resultando não apenas na criação dos espaços, mas também de imaginários sobre os espaços, para serem consumidos visualmente até mesmo por quem não necessariamente os frequenta fisicamente.

\section{Cosmopolitismo e ubiquidade}

A investigação desse processo de "hipsterização" do bairro parte, sobretudo, da observação de fenômenos perceptíveis a partir da escala da rua e das calçadas. Para constatar as análises até aqui apresentadas, o trabalho etnográfico foi fortemente mediado pela observação do território: iniciou-se com uma série de caminhadas inspirado por reflexões metodológicas propostas por Arantes e Silva (2009) - onde pude perceber em quais ruas e em quais localidades havia, no nível da calçada, agrupamentos de jovens adultos socializando enquanto tomam cafés especiais ou cervejas artesanais, prestigiam eventos de lançamento de publicações independentes, ou fazem compras em pequenas feiras periódicas de produtos artesanais, autorais e de design.

A partir dessas observações, passei a elaborar uma série de mapas (com o suporte do Google Maps) que, quando sobrepostos, permitiram a visualização de padrões de concentração de comércios (novos e antigos), instituições, espaços de interesse, vias de acesso, perímetro dos bairros, localização de áreas de intervenção do Estado, concentração de lançamentos imobiliários e o perímetro de grandes projetos de políticas públicas que tenham como objetivo diferentes formas de "requalificação" da região central de São Paulo. Esses mapeamentos permitiram, então, uma delimitação maior do perímetro do campo de pesquisa, e uma maior precisão das observações etnográficas no nível da rua, de perto e de dentro (Magnani, 2012). Além disso, com 
uma área de pesquisa mais delimitada, pude realizar um walking census (inspirado pela metodologia utilizada por Zukin, Kasinitz e Cheng (2015) em uma pesquisa em ruas de comércio no Norte global), em que eu observei, sistematizei e elaborei uma classificação tipológica quanto às características e atividades de cada local, os públicos a quem se destinam, os padrões estéticos observáveis nas fachadas, nos ambientes e na ocupação das calçadas. Este exercício, sempre acompanhado de uma tabulação sistemática das observações, foi repetido diversas vezes ao longo da pesquisa de campo - e a comparação das tabulações tornou possível visualizar, de forma concreta, as "mudanças" no bairro percebidas pelos interlocutores - como, por exemplo, onde havia novas lojas ou bares sendo inaugurados, onde havia estabelecimentos comerciais fechando, sendo substituídos ou reformados, onde havia novos empreendimentos imobiliários sendo anunciados. Como recurso adicional, o Google Street View também foi utilizado para observar as fachadas dos endereços pesquisados em períodos anteriores ao início da pesquisa, de forma a constatar o que havia em cada local antes da inauguração dos comércios hipster atuais (inspirado pela técnica de comparação das imagens dos mesmos locais em diferentes anos, utilizada por Frúgoli Jr. E Chizzolini (2017)).

Esse mapeamento sistemático, somado às inúmeras conversas com frequentadores, trabalhadores e funcionários destes estabelecimentos - além de vizinhos, moradores e frequentadores do bairro - permitiu a observação e compreensão de como estas unidades microlocais de sociabilidade dialogam ou fazem parte da estruturação de um nível muito mais amplo, da cidade (Cordeiro, 2001: 128). No entanto, em muitas das conversas em campo, no acompanhamento de notícias na imprensa, na observação das postagens que estes estabelecimentos fazem nas redes sociais e na participação de uma comunidade de moradores da região da Santa Cecília e Vila Buarque no Facebook, ficava evidente que o fenômeno, ainda que observado de forma fortemente territorializada, remete o tempo todo a referências, modos de vida, valores, crenças e significados de ampla circulação em escala global e desterritorializada.

Uma frase ouvida durante a pesquisa de campo indica esse aspecto global que se materializa localmente - durante um debate de que participei sobre o tema da gentrification, organizado por Alex Sartori, arquiteto participante do grupo de moradores do bairro no Facebook, Alex comentou, ironicamente, ao comentar sobre a estética destes estabelecimentos: “eu não sei se estou em um café, ou se estou dentro do 
Pinterest". Neste comentário, ele fazia referência a uma rede social digital de compartilhamento e pesquisa de referências visuais, amplamente utilizada por profissionais de áreas criativas, como arquitetura, design, moda e decoração. Efetivamente, a observação desta ferramenta permitiu constatar que muitas das características visuais percebidas nos novos comércios da Vila Buarque (como materiais e elementos decorativos, por exemplo) também podem ser observadas em estabelecimentos similares em cidades tão distintas como Tóquio, Estocolmo ou Chicago. De uma perspectiva mais prática, o Pinterest funciona como um grande catálogo colaborativo de soluções práticas, criativas e muitas vezes de baixo custo que podem ser facilmente adotadas por empreendedores que abrem seus primeiros negócios - soluções estas que são avaliadas a partir do repertório estético dos criadores destes estabelecimentos e adotadas como saídas para contornar problemas como espaço reduzido ou orçamento restrito para a aquisição de mobiliário ou contratação de arquitetos para a elaboração visual do espaço. Adicionalmente, redes sociais voltadas para a circulação de referências visuais (como Pinterest e Instagram) influenciam não somente a confecção dos espaços por seus responsáveis, mas também o imaginário e as expectativas de consumo de clientes atentos a essas mesmas tendências.

Ironicamente, ao mesmo passo em que cada um desses estabelecimentos seja concebido com a intenção de produzir distinção com relação aos demais comércios da cidade, com produtos que sempre são acompanhados de adjetivos que prometem exclusividade, também é notável como todos eles são organizados de acordo com um conjunto de referências compartilhadas que, em diversos aspectos, acabam por apontar mais para uma padronização de elementos associados ao universo hipster do que a uma despadronização. Isso se reflete tanto nas já apontadas semelhanças entre alguns estabelecimentos observados na Vila Buarque e referências visuais de lugares comparáveis em outras grandes cidades no mundo, como também em semelhanças entre estabelecimentos dentro do próprio campo de pesquisa. Alguns exemplos são a presença de três lojas que combinam cafeterias e lojas de plantas e acessórios de decoração, duas lojas de alimentos orgânicos vendidos sob um modelo de transparência dos custos e comércio justo, duas antigas bancas de jornal reconvertidas em espaços para eventos culturais e venda de publicações de editoras independentes, ou ao menos três cervejarias especializadas em cervejas artesanais tiradas diretamente da torneira - todos esses 
estabelecimentos dentro de um raio de poucos quilômetros, nos bairros da Vila Buarque, Santa Cecília e República.

Essa aparente contradição entre uma tentativa de produzir distinção com relação aos demais estabelecimentos existentes na cidade e aos produtos por eles oferecidos, ao mesmo tempo em que há uma forte sintonia entre esses comércios hipster - tanto os da região central de São Paulo, como também entre os estabelecimentos comparáveis em cidades por todo o mundo pode ser melhor compreendida com um enfoque no conceito de cosmopolitismo.

Tanto o uso da categoria hipster como a adoção de modos de vida e hábitos de consumo a ela associadas são sincrônicas ao avanço da internet e das redes sociais digitais, e à rápida expansão da possibilidade de compartilhamento e difusão de informações em escala global, teoricamente por qualquer pessoa. Entretanto, essa difusão é marcada pela hegemonia de modos de vida, de consumo e comportamento das grandes cidades do Norte global sobre todo o mundo - de forma que a categoria hipster passa a ser uma palavra que viaja juntamente com as tendências político-econômicas que contribuem para a reconfiguração das grandes metrópoles ao redor do mundo, carregando consigo uma série de códigos e significados que também viajam e que, por sua vez, são traduzidos, apropriados e ressignificados em cada contexto local. Neste caso, por se tratarem de pessoas com recursos econômicos, sociais e culturais para efetivamente acessar modos de vida globais e concretamente traduzir parte desses códigos para o contexto local a partir de seus repertórios pessoais e profissionais, os hipsters podem ser comparados a um segmento cosmopolita das camadas médias relatado por Gilberto Velho, a partir de suas pesquisas no bairro de Copacabana nos anos 1970 , por onde

\footnotetext{
circulavam pessoas de várias partes do mundo, da área dos negócios, do entretenimento, do meio artístico-cultural, entre outros. Suas referências eram claramente internacionais. Viajar pelo mundo era atividade rotineira e participavam de redes sociais intercontinentais. Falavam, pelo menos, mais de uma língua, quando não três ou quatro, do mesmo modo que elites sociais da cosmopolita Palmira, nos séculos II e III, que, segundo Paul Veyne (2009), falavam grego, latim e aramaico" (Velho, 2010: 18)
}

Para Velho, esses sujeitos cosmopolitas desempenham um papel de mediadores na sociedade urbana moderna: são dotados de uma "plasticidade sociocultural que se manifesta na capacidade de transitar e, em situações específicas, de desempenhar o papel de mediador entre distintos grupos e códigos (...), com potencial de desenvolver 
capacidade e/ou empatia de perceber e decifrar pontos de vista e perspectivas de categorias sociais, correntes culturais e de indivíduos específicos" (Idem: 19). É importante ressaltar, entretanto, que o conceito de cosmopolitismo não se refere apenas a camadas privilegiadas da sociedade. Stuart Hall afirma que

\begin{abstract}
há um 'cosmopolitismo da camada de cima' - empreendedores globais seguindo os caminhos do poder corporativo global e os circuitos de investimento e capitais globais, que não conseguem dizer em qual aeroporto estão porque todos eles parecem o mesmo, e que têm apartamentos em três continentes. Esse é um cosmopolitismo global de um tipo muito limitado, mas é muito diferente de um 'cosmopolitismo da camada de baixo' - pessoas levadas a cruzar fronteiras, obrigadas a se desenraizarem de suas casas, seus lugares e suas famílias, vivendo em campos transitórios ou se pendurando em paus-de-arara, em barcos furados ou no fundo de trens e aviões para chegar a algum outro lugar" (Werbner e Hall, 2008: 346).
\end{abstract}

Evidentemente, os agentes responsáveis pelo processo de hipsterização de bairros centrais de grandes cidades se aproximam mais dos cosmopolitas da camada de cima, mas não têm os mesmos recursos e a livre circulação dos jetsetters descritos por Hall. Seus recursos econômicos são mais limitados, e o alcance das traduções e importações que eles realizam é mais limitado.

\footnotetext{
Isso significa que muitos dos valores, ideias e referências que esses cosmopolitas das camadas médias trazem consigo, quando não se refletem apenas em suas escolhas privadas e em seus estilos de vida individuais, acabam por serem reconhecidos e validados somente pelo reduzido universo de pessoas que também compartilham dos mesmos gostos e interesses associados ao universo hipster (Alcântara, 2019: 118).
}

Esse repertório global que encontra no universo hipster um potente vetor de propagação não se restringe somente a gostos estéticos e modos de consumo. O caso já citado da popularização do termo "gentrificação" como denúncia a percepções de mudanças indesejadas no bairro e no entorno é um bom exemplo de que trata-se de uma circulação, em escala global, de diferentes formas de se pensar a cidade e de estar na cidade: cientes de seus privilégios de classe, informados sobre os potenciais reflexos de suas preferências (residenciais, de consumo e de lazer) nas dinâmicas urbanas, e desejantes da manutenção da diversidade e da heterogeneidade da mesma região central onde eles mesmos optam por se instalar, a "gentrificação" vira ao mesmo tempo uma palavra de denúncia e de autocrítica. Mas existem outros casos que ilustram o quanto o universo hipster remete a novas formas de se pensar a vida urbana: no âmbito dos novos negócios pesquisados, é notável a proeminência de iniciativas que privilegiam, em seus 
produtos e seus discursos, posturas progressistas e que reivindicam novas formas de comércio. Os maiores exemplos são as duas lojas que comercializam alimentos sem agrotóxicos transparecendo aos clientes os preços de custo de cada produto, e deixando explícita qual é a porcentagem adicional adicionada a este preço para que as lojas possam se sustentar - em uma postura bastante distinta do formato de opacidade sobre os preços e maximização dos lucros do comércio em geral. Outros exemplos são um bar voltado criado, segundo sua proprietária, para ser um lugar seguro para que mulheres possam sair com segurança à noite, e que possa servir como um ponto de resistência para a comunidade LGBTQI+; e um café onde mães de crianças pequenas encontram estrutura e acolhimento para que possam levar seus filhos no meio do dia, enquanto fazem reuniões ou trabalham nas mesas disponíveis. Há, nesses casos, um senso de oportunidade destes empreendedores, de reconhecer que há em seu entorno uma concentração de potenciais clientes que valorizam posturas e atitudes diferentes do padrão hegemônico que rege a maioria dos outros estabelecimentos na cidade.

Efetivamente, se uma característica das pessoas classificáveis com a categoria hipster é a tendência de buscar traços de distinção que denotem uma postura mais descolada, moderna, progressista e cosmopolita do que seus pares pertencentes aos seus mesmos círculos socioeconômicos, a adoção de novas formas de estar na cidade representam um importante marcador de ruptura com os modos de vida predominantes entre as elites paulistanas. Assim, as escolhas políticas de viver no Centro e fruir de sua diversidade, caminhar a pé ou andar de bicicleta, usar transporte público e abrir mão de possuir um carro, morar próximo ao trabalho e aos seus principais locais de interesse, valorizar o comércio local e a produção em pequena escala, consumir alimentos orgânicos e artesanais, usufruir intensamente das áreas verdes, equipamentos e manifestações culturais e espaços de lazer abundantes no entorno, participar de (novas) articulações da esfera civil em defesa de uma manutenção ou de melhoramentos de determinadas características do bairro ou da cidade tornam-se um importante reforço identitário que produzem um grande contraste com modos de vida e de consumo orientados para a segregação em condomínios e em bairros mais homogêneos e o uso exclusivo do carro como meio de locomoção na cidade, por exemplo.

Neste aspecto, é útil recorrer às três tipologias propostas por Jacques Donzelot (2004) para interpretar diferentes tipos de mobilidades (ou imobilidades) de distintas populações em uma grande metrópole. $\mathrm{O}$ autor sugere que a circulação das camadas médias e baixas vivem uma "mobilidade constrangida" em bairros mais periféricos (constrangimento este que se dá tanto pelo acesso restrito a recursos econômicos como pela territorialização de suas redes de sociabilidade). Já as camadas médias e altas optam por viver uma "imobilidade voluntária" em 
bairros de baixa heterogeneidade social (com uma maior sensação de segurança por viver entre iguais) - e é deste perfil que os hipsters buscam se destacar com suas escolhas e atitudes. Segundo o autor, os moradores de camadas médias e superiores que optam voluntariamente por viver na região central tendem a valorizar a ubiquidade: estabelecem suas vidas no Centro, mas têm acesso fácil a toda parte; valorizam a proximidade de tudo aquilo que lhes importa em seus bairros, mas também a velocidade das redes reais ou virtuais que lhes permitem se conectar facilmente com qualquer outro ponto do globo no mesmo ritmo em que vivem habitualmente. Segundo Donzelot, "podem reduzir o tempo dos deslocamentos cotidianos, mas também viver bem no ritmo do mundo, escapando dos constrangimentos do movimento dos demais habitantes locais" (Donzelot, 2004: 36).

\section{Considerações finais}

Ao longo deste artigo, busquei demonstrar que, mais do que um estilo passageiro de moda ou uma mera importação de estrangeirismos, o fenômeno da "hipsterização" reflete uma intrincada rede de referências, preferências estéticas e posicionamentos políticos que não se restringem somente aos estilos de vida individuais das pessoas classificáveis com o termo hipster. Trata-se de um conjunto heterogêneo de tendências globais que, quando acessadas por pessoas munidas de repertórios para sua identificação, e detentoras de capital econômico, social e criativo suficientes para sua tradução para o contexto local, são capazes de reconfigurar a imagem e a desejabilidade de bairros inteiros da região central da cidade por segmentos de alta renda - na contramão da tendência histórica de deslocamento das elites para cada vez mais longe do Centro.

A etnografia realizada na Vila Buarque demonstra que, quando isso ocorre, resulta em um cenário em que pessoas hipsters (ainda que essa seja uma classificação situacional, heteronômica e jocosa) passam a preferir e a consumir produtos hipsters (com alto nível de especialização em seu preparo, de forma a produzir distinção com relação aos demais produtos disponíveis no mercado), juntamente com seus amigos hipsters (uma vez que todas as práticas associadas à categoria costumam ser validadas $\mathrm{e}$ compartilhadas apenas por pessoas munidas dos mesmos repertórios), em estabelecimentos hipsters (criados seguindo tendências globais de decoração), criados e mantidos por empreendedores hipsters (que encontraram em novas atividades, voltadas a seus pares, oportunidades de ruptura de suas trajetórias profissionais anteriores para apostar em novos ofícios), em bairros hipsters - onde a presença desses 
estabelecimentos e a concentração desse perfil de público provocam discussões sobre transformações na paisagem e o potencial desse fenômeno interferir significativamente nas dinâmicas econômicas e sociais da região central da cidade.

\section{REFERÊNCIAS}

ALCÂNTARA, Maurício F. Síntomas versus diagnósticos: hipsters y gentrification en Vila Buarque, São Paulo. Investiga Territorios, n. 7, p. 31-45, $2018 \mathrm{a}$.

. Gentrificação e "hipsterização": um estudo sobre a Vila Buarque (São Paulo, Brasil). Sociabilidades Urbanas - Revista de Antropologia e Sociologia, v. 2, n. 6, p. 31-48, nov. 2018 b.

. "Hipsterização" no centro de São Paulo: consumo, trabalho e produção da cidade. Dissertação de mestrado. São Paulo: Universidade de São Paulo, 2019.

BOURDIEU, Pierre. Outline of a Theory of Practice. Cambridge: Cambridge University Press, 1977.

. A Distinção: Crítica Social do Julgamento. Porto Alegre: Zouk, 2011.

CORDEIRO, Graça. Í. Territórios e identidade: sobre escalas de organização socioespacial num bairro de Lisboa. Revista Estudos Históricos, v. 2, n. 28, p. 125-142, 25 fev. 2001.

DAVIDSON, Mark; LEES, Loretta. New-Build 'Gentrification' and London's Riverside Renaissance. Environment and Planning A: Economy and Space, v. 37, n. 7, p. 1165-1190, 1 jul. 2005.

DONZELOT, Jacques. La ville à trois vitesses: relégation, périurbanisation, gentrification. Esprit, abr. 2004.

FRÚGOLI JR., Heitor. Centralidade em São Paulo: trajetórias, conflitos e negociações na metrópole. São Paulo: Edusp, 2000.

FRÚGOLI JR., Heitor.; CHIZZOLINI, Bianca B. Relações entre Etnografia Face a Face e Imagens do Google Street View: Uma Pesquisa sobre Usuários de Crack nas Ruas do Centro de São Paulo. GIS - Gesto, Imagem e Som - Revista de Antropologia, v. 2, n. 1, 29 maio 2017. 
LEES, Loretta. Super-gentrification: The Case of Brooklyn Heights, New York City: Urban Studies, 2 jul. 2016.

LLOYD, Richard. Neo-Bohemia: Art and Commerce in the Postindustrial City. Nova York: Routledge, 2010.

MAGNANI, José Guilherme. C. Da periferia ao centro: trajetórias de pesquisa em antropologia urbana. São Paulo: Terceiro Nome, 2012.

MISKOLCI, Richard. Estranhos no paraíso: notas sobre os usos de aplicativos de busca de parceiros sexuais em San Francisco. Cadernos Pagu, n. 47, 2016.

MORETTI, Enrico. The New Geography of Jobs. Boston: Mariner Books, 2013.

MÜLLER, Nice L. A área central da cidade. In: AZEVEDO, A. DE (Ed.). A cidade de São Paulo: Estudos de geografia urbana. São Paulo: Cia. Editora Nacional, 1958. v. IIIp. 121-182.

OCEJO, Richard E. Masters of Craft: Old Jobs in the New Urban Economy. Princeton: Princeton University Press, 2017.

PHILLIPS, Martin. Rural gentrification and the processes of class colonisation. Journal of Rural Studies, v. 9, n. 2, p. 123-140, 1 abr. 1993.

SILVA, Helio R. S. A situação etnográfica: andar e ver. Horizontes Antropológicos, v. 15, n. 32, p. 171-188, dez. 2009.

SMITH, Darren The Politics of Studentification and '(Un)balanced' Urban Populations: Lessons for Gentrification and Sustainable Communities?: Urban Studies, 1 nov. 2008.

SMITH, Neil. Toward a Theory of Gentrification A Back to the City Movement by Capital, not People. Journal of the American Planning Association, v. 45, n. 4, p. 538548, 1 out. 1979.

VELHO, Gilberto. Projeto e metamorfose: antropologia das sociedades complexas. Rio de Janeiro: J. Zahar Editor, 1994.

. Metrópole, cosmopolitismo e mediação. Horizontes Antropológicos, v. 16, n. 33, p. 15-23, jun. 2010.

WERBNER, Pnina.; HALL, Stuart. Cosmopolitanism, Globalisation and Diaspora: Stuart Hall in Conversation with Pnina Webner. In: WERBNER, P. (Ed.). Anthropology and the new cosmopolitanism: rooted, feminist and vernacular perspectives. ASA monographs. New York: Berg, 2008. p. 345-360.

ZUKIN, Sharon. Loft Living: Culture and Capital in Urban Change. New Brunswick, N.J: Rutgers University Press, 1989.

. Naked City: The Death and Life of Authentic Urban Places. Oxford: Oxford University Press, 2011. 
ZUKIN, Sharon; KASINITZ, Philip.; CHEN, Xiangming. Global Cities, Local Streets: Everyday Diversity from New York to Shanghai. Nova York: Routledge, 2015.

Recebido: $01 / 06 / 2020$

Aprovado: 04/09/2020 